\title{
Língua(gem) e identidade: a estranha-familiar língua da escola ${ }^{1}$
}

\author{
Language and Identity: the uncanny \\ language at school
}

Angela Derlise Stübe Netto*

Universidade do Contestado - UNC - Concórdia - SC

\begin{abstract}
RESUMO: Neste estudo, analisamos narrativas de professores de língua portuguesa (LP) que não possuem exclusivamente essa língua em sua inscriçāo no campo da linguagem para, com isso, pensar sua relação com a(s) língua(s) da/na escola. Para a constituição de nosso corpus, entrevistamos catorze professores da educação básica da rede pública na região de Concórdia, SC, cuja história sociocultural é marcada pela imigração européia. Nas análises, observamos que a escola assume uma prática de silenciar uma história marcadamente plural, sem torná-la dizível, deixando assim de trabalhar a relação com a alteridade linguística e com as memórias outras que constituem os sujeitos de nossa pesquisa. Essa questão abrange aspectos não só de ordem educacional mas também histórica, social, política e, consequentemente, identitária.
\end{abstract}

PALAVRAS-CHAVE: identidade, formação de professores, pluralidade linguística, differance.

ABSTRACT: This study analyzes narratives produced by teachers of Portuguese who do not have only this language in their langagière inscription, with the purpose of reflecting on their relationship with the language(s) at school. Our corpus is composed by 14 interviews with public basic school teachers in the region of Concórdia (Santa Catarina state, Southern Brazil) whose socio-cultural history is featured by European immigration. Our analyses have shown that school practice keeps in silence a history that is remarkably plural, without allowing it becomes utterable and failing to work out its relationship with the linguistic

${ }^{1}$ Este texto é fruto de minha tese de doutoramento, defendida em julho de 2008, no Instituto de Estudos da Linguagem, da UNICAMP, sob orientação da profa. Dra. Maria José Rodrigues Faria Coracini, e contou com o apoio financeiro da FAPESP. Também foi apresentado no II Congresso Latino-Americano sobre Formação de Professores de Línguas, no Rio de Janeiro, em 2008, e uma versão alterada consta dos Anais deste.

*adsnetto@hotmail.com, angelanetto@uncnet.br 
otherness and with the memories which constitute the subjects of our research. This complex issue involves aspects whose nature is not only educational, but also historic, social, and, consequently, identitarian.

KEYWORDS: identity, Teachers' training / education, linguistic plurality, differance.

\section{Introdução}

Pensar a formação de professores de língua implica uma ética e uma responsabilidade frente à relação desses profissionais com o seu objeto de saber. Entendemos que as práticas discursivas e não discursivas dos enunciadores se constróem a partir de um arquivo, sempre-já histórico e social, do que seja o papel do professor, do que seja ensinar e aprender e quais discursos podem ou não circular em sala de aula. Variados estudos apontam que, nesses arquivos, prepondera uma visão calcada no imaginário de língua portuguesa como língua materna de quem nasce no Brasil, com uma concepção logocêntrica de sujeito (NETTO, 2008, 2007; CORACINI, 2007; PAYER, 1999).

Neste texto analisamos narrativas de professores de Língua Portuguesa (LP) a respeito de sua relação com a(s) língua(s) na escola para, com isso, pensar implicações no processo de formação e de constituição identitária. Participaram de nossa pesquisa catorze professores da educação básica, da rede pública de ensino, da região de Concórdia, SC, cuja história sócio-cultural é marcada pela imigração européia, com a presença marcante das línguas alemã, italiana e polonesa. A construção metodológica orientou-se por relatos escritos sobre a história de formação linguística e profissional do professor, seguida de uma entrevista pautada em elementos desse relato.

O pressuposto que sustenta nossa investigação é de que, no imaginário, circula a ideia de que a LP é a língua materna (LM) de quem nasce no Brasil. Entretanto, muitos professores, como podemos verificar no corpus, não possuem exclusivamente a LP como língua de inscrição na linguagem. Formulamos, então, a hipótese de que tal situação gera um conflito, uma constante tensão para o professor que, certamente, repercute na sua prática, no seu processo de formação e nos seus processos identificatórios. Essa história de vida caracterizada por uma constituição linguística, marcadamente plural, traz incidências para a formação de professores de LP e para o modo de conceber e de se relacionar com seu objeto de saber: a língua.

Teoricamente, situamo-nos na interface de teorias que trabalham com a noção de sujeito da linguagem, compreendido na sua contradição inerente, 
sustentado pelo desejo e pelo inconsciente. A partir das análises, concebemos a noção de língua atravessada pela heterogeneidade, que constitui o entre-línguas.

Neste texto, questionamos como os professores narram a gestão da língua na escola. Tal reflexão poderá fornecer elementos importantes para pensarmos a identidade de professores em contextos plurilíngues, consequentemente, com incidências para a formação deles.

\section{Entre o mesmo e o diferente}

Foucault (1988), ao longo de sua obra, efetua uma arqueologia da subjetividade e uma genealogia do sujeito, nas quais busca, nos arquivos, os modos de constituição do sujeito e os processos de subjetivação, desenhando uma subjetividade em movimento e continuamente produzida. A produção dessas formas de subjetivação se dá pela constituição de mesmas ou de outras discursividades que se instauram pelos e sobre os enunciadores (NETTO, 2006). Há uma função normalizadora dos lugares e dos modos em que esses discursos podem circular. Instauram-se, assim, regimes de verdade; o modo de gestão desses discursos produz verdades para / do enunciador, arquivos que se inscrevem no enunciador. Foucault (1995) justifica:

[c]ada sociedade tem seu regime de verdade, sua 'política geral' de verdade: isto é, os tipos de discurso que ela acolhe e faz funcionar como verdadeiros; os mecanismos e instâncias que permitem distinguir os enunciados verdadeiros dos falsos, a maneira como se sanciona uns e outros; as técnicas e os procedimentos que são valorizados para a obtenção da verdade; o estatuto daqueles que têm o encargo de dizer o que funciona como verdadeiro (p.12).

Nos jogos de verdade, em um exame de si mesmo, a relação do enunciador com as práticas discursivas confere a ele a possibilidade de uma identidade (sempre ilusória e ficcional). É uma possibilidade de se dizer em um grupo e em uma época. Para o citado autor, "a questão é ver como, historicamente, efeitos de verdade são produzidos no interior de discursos e não o que eles podem ou não carregar (como algo intrínseco) de científico e / ou verdadeiro" (NETTO, 2006, p.516).

Para Foucault (1996, p. 8-9), "em toda sociedade, a produção do discurso é ao mesmo tempo controlada, selecionada, organizada e redistribuída por um certo número de procedimentos que têm por função conjurar seus poderes e perigos." Neste trabalho, analisamos a multiplicidade de modos de gestão dos 
indivíduos que podem ser percebidos nas políticas linguísticas implementadas na / pela instituição escolar. Como funcionam os procedimentos em relação à gestão da língua? Quais são eles? Como incidem nos processos identificatórios que o enunciador deixa resvalar pela linguagem? Para discutir isso, vamos partir de alguns recortes discursivos $(\mathrm{RD})$ :

$\mathrm{RD}^{2} 6^{2}:$ [... ] a primeira língua que aprendi foi o alemão e considero minha $L M($...) I então por causa da minha entrada na escola / eu tive que deixar de lado o alemão // que foi muito difícil eu tirar à força / (...) tanto que o alemão eu tive que esquecer III ficou uma marca muito forte / essa perda né I/ foi como uma cicatriz / (...) as frases que me marcaram no ensino da $L P$ foi 'o barquinho é amarelo' 'a banana é amarela' 'a laranja é amarela' isso tá na minha cabeça como se fosse hoje se eu tivesse hoje na sala de aula e lendo isso tanto que me marcou // era trabalhado assim né / (...) / então por essa dificuldade de eu me adaptar com a LP por causa da minha LM / eu acho que ficou impregnado um // um // uma certa / como eu posso dizer I/ uma marca I/I negativa né / isso em relação à LP né / (...) // então pra mim foi um desafio muito grande também estar cursando / estar fazendo um curso de letras / eu fiquei com receio / eu / pra mim na época / em que comecei a cursar o curso de graduação em português / eu acho que o português era um dragão / mas eu queria ter forças para enfrentar esse dragão (...) meu objetivo maior é trabalhar segunda língua, não a LP//I eu ainda tenho assim um certo receio $\left[\text { [...] (E2; p. } 8^{3}\right)^{4}$

No funcionamento discursivo do $\mathrm{RD} 16$, de E2, percebemos a repetição de uma série de nexos que indiciam relaçóes causais, conclusivas ou consecutivas: 'então por causa', 'tanto que', 'então por essa dificuldade', 'por causa da minha LM', 'então pra mim', que conferem uma ilusória linearidade ao dizer e uma tentativa de coerência para a narrativa, que lhe permitiriam uma textualidade. Esses nexos podem gerar uma falsa impressão de um passado cujas

\footnotetext{
${ }^{2}$ A sigla RD indica "recorte discursivo", seguida do número correspondente ao recorte na composição total do corpus.

${ }^{3}$ A primeira letra indica se o recorte foi extraído do texto escrito ( $\mathrm{T}$ ) ou da entrevista (E), seguida do número que identifica o professor. Após o ponto-e-vírgula, referenciamos o número da página em que encontramos o recorte na compilação dos textos e da transcrição das entrevistas.

${ }^{4}$ Esse mesmo RD, sob outros aspectos, foi analisado no artigo publicado em Netto (2007).
} 
tensões e conflitos foram resolvidos. Todavia, são marcas de rupturas e não uma linearidade, pois, ao tentar apagar algo, marca-se. Ao tentar aparentar o um, escamotear a heterogeneidade, instaura-se a alteridade do / no discurso.

Tal funcionamento tem como preço (tentar) apagar uma historicidade e subsumir uma série de acontecimentos, lançados ao esquecimento, em função de uma resistência inconsciente, pois gera sofrimento "deixar de lado", ou "tirar à força", a língua que o professor considera a sua língua materna, no caso, a língua alemã, como ele afirma no início do recorte.

Percebemos, nesse recorte, uma ruptura pela presença de duas posiçõessujeito nessa enunciação: uma posição ligada à língua alemã; outra ligada à língua portuguesa, e esta não deixa aquela falar. No mesmo enunciador, duas posições 'falam'. A posição de 'alemão' está triste por ter sua voz interditada - o pai o interdita, a mãe (LM) foi tirada à força. Entretanto, o 'alemão' ainda quer 'falar'. Tanto que esse professor, inúmeras vezes, chegava à aula falando em alemão. ${ }^{5}$ Apesar de "ter sido tirado à força", o alemão está lá ainda. E busca um espaço para (se) dizer; espaço para dizer (d) essa interdição. Já a outra posição, ligada à língua portuguesa, procura interditar o que não pode ou não deve ser dito. Institucionalmente, indicia a gestão das línguas e a normalização dos enunciadores. Nesse jogo entre essas posiçōes escapa a clivagem do sujeito e do discurso.

Resta questionar: $e$ as hesitações, as pausas, as vacilações que funcionam nesse RD? Quais efeitos de sentido podem ter? Para compreender um pouco mais sobre o processo de hesitação no dizer, apoiamo-nos na tese de Paulillo (2004), que discute a enunciação vacilante, como modos de funcionamento da heterogeneidade no discurso de si. Para a autora, "na enunciação vacilante, tão logo um segmento de valor representacional é enunciado, seu poder de nominação é suspenso pelo atravessamento de modalizações cujo efeito é fazer tombar os sentidos que o dizer inscreve na dimensão da provisoriedade, da incompletude" (2004, p. 3). Essas hesitações marcam, no fio discursivo, a heterogeneidade constitutiva de todo processo de subjetivação. A produção de discursos não é controlável, a ordem do discurso esburaca-se, é heterogênea e marcada pela falta, porque o sujeito é constitutivamente clivado e barrado pela linguagem. Envolve sempre-já "poderes e perigos" (FOUCAULT, 1996, p. 9).

${ }^{5}$ Vale esclarecer que os professores entrevistados foram todos meus alunos na UNC - Universidade do Contestado, Campus Concórdia, SC, durante o Curso de Graduação em Letras, o que me possibilita a referência a esse professor falar em alemão com os colegas e comigo em diversos momentos da aula, mas especialmente na chegada à sala de aula. 
Percebemos, ao longo de todo o recorte, pausas curtas (/), pausas longas (///), retomadas e vacilações do/no dizer (um // um // uma certa / como eu posso dizer /). Um dos possíveis sentidos para esse funcionamento é o da hesitação. Hesita porque, de algum modo, toca o sujeito - 'foi muito difícil eu tirar à força I/I tanto que o alemão eu tive que esquecer'; 'como eu posso dizer // uma marca // I negativa né' (grifos nossos) - que deixa escapar, na materialidade linguística, representaçõos de si, traços de identificação, tais como, a filiação em uma pertença fortemente marcada pela manutenção de traços da língua alemã; a resistência à língua portuguesa, que o inscreve em outra filiação, a da brasilidade. Ele está e não está inscrito na pertença "sou alemão"; está e não está inscrito na pertença "sou brasileiro". As (não) fronteiras se esboroam: "ora, jamais esta língua, a única que estou votado a falar, enquanto falar me for possível, e em vida e na morte, jamais esta língua única, estás a ver, virá a ser minha. Nunca na verdade o foi" (DERRIDA, 2001, p. 14).

Destaca-se, no recorte, também a interdição da língua em função de sua inscrição em uma ordem dada pela escola - "por causa da minha entrada na escola tive que deixar de lado o alemão". Todavia, continua ao 'lado', marca sua presença-ausência: o alemão é, ao mesmo tempo, o estranho à norma gestora da escola e o familiar ao enunciador.

Novamente, notamos que o enunciador está sujeito a uma dupla injunção, que gera efeitos nos processos identificatórios: da história familiar, de ascendência alemã, e da institucional-escolar, que, na gestão de línguas, pressupõe a língua portuguesa como ideal.

No gesto de interdição da / na língua, apresentado no recorte (RD16), não é o arquivo do passado que está sendo interditado, mas é uma identificação que está sendo sufocada. Não é o passado que o professor está presentificando, ele não está resgatando algo, é, pois, um movimento a posteriori, um 'passado' que é sempre invenção, construído pelo olhar do presente, cria uma narrativa ficcional que busca, insconscientemente, dar uma explicação ou possível coerência à sua história. A narrativa está o tempo todo constituindo o enunciador, compondo as suas identificações.

Os traços da história e da cultura ficam impregnados, como diz o professor: "o alemão eu tive que esquecer" (...) "eu acho que ficou impregnado um // um // uma certa / como eu posso dizer // uma marca /I/ negativa né / isso em relação à língua portuguesa nể. Quanto mais fala que tem de esquecer, mais marca a presença / ausência. Chama-nos a atenção que, no intradiscurso, essa língua é introduzida pelo artigo definido masculino singular 'o', o alemão (não 
a língua alemã): aquela língua tanto do aconchego, na qual ele pode se contar, quanto da figura da lei, do interdito paterno.

Dito isso, questionamos: qual é a língua da escola? Ao narrar seu ingresso na escola, alguns significantes se inscreveram e fizeram memória, sendo ressignificados e enunciados na entrevista: "As frases que me marcaram no ensino da LP foi [sic] 'o barquinho é amarelo' 'a banana é amarela' 'a laranja é amarela' isso tá na minha cabeça como se fosse hoje se eu tivesse hoje na sala de aula e lendo isso tanto que me marcou // Era trabalhado assim nél".

Observamos a repetição de uma estrutura do livro didático (LD) - frases curtas, repetidas, cujo objetivo é o ensino da regra gramatical em detrimento da constituição do sentido. Em outra ocasião, questionado sobre esses enunciados, o professor afirmou que "lembro-me das frases escritas no quadro negro, inclusive o coral das vozes que fazíamos quando tínhamos que repetir as frases. Acredito que era uma espécie de cartilha." ${ }^{6}$

São recordações fragmentadas, que permanecem na memória do professor, pois os eventos ligados a essas recordaçôes têm importância psíquica na experiência do enunciador. Tais eventos causaram profunda impressã $0^{7} \mathrm{e}$ inscreveram traços na memória. Todavia, não são eventos 'recuperáveis', mas impressões, pensamentos inconscientes, sendo isso (re)significado a posteriori, cujo conteúdo pode estar ligado por elos simbólicos às lembranças encobridoras (FREUD, 1899).

Da análise do RD16, podemos depreender que a língua da escola imprimiu-se no professor, deixando traços indeléveis em sua identidade. Essa língua se apresenta como repetição e como desvinculada da realidade do então aluno. Na escola, há a tentativa de gerir a língua na busca do um, da unicidade e do escamoteamento da heterogeneidade, para sustentar a ilusão de monolinguismo.

\footnotetext{
${ }^{6}$ Consulta realizada após a entrevista.

7 O vocábulo 'impressão', que destacamos em nosso texto, provém, em sua raiz latina, de impressionis, ação de calcar, marcar por pressão, o que indicia sentidos como ato ou efeito de imprimir (se), marca ou vestígio deixado por esse ato (HOUAISS, 2007, p. 1585).
} 


\section{Entre a pluralidade e a normatização}

$\mathrm{Na}$ escola 'passeiam' várias línguas, convivem variadas culturas, arquivos, representações do que seja ensinar e aprender línguas. Pela análise até aqui empreendida, podemos perceber que a língua da escola é fragmentária, mas pretende a ilusão do todo, de unicidade. Contudo, a heterogeneidade, a clivagem, o ser-estar-entre-línguas escapa e instaura "a língua híbrida do enunciador", o que gera conflitos nesse processo de gestão da língua e dos enunciadores, tal como é possível notar também no funcionamento do $\mathrm{RD}$ a seguir:

(RD19): A professora colocava / na primeira série / uma cadeira de madeira que tinha / ela cortou as pernas da cadeira e colocou no canto da sala e era como se fosse o palco e a gente subia na cadeira pra ler / ler as historinhas / o barquinho amarela / lá aquelas coisas lá do quadro que ela escrevia / mas a gente subia no palco // é uma pena que no meu caso eu hoje tenho receio / embora tenha perdido nos últimos tempos / em função da // da função, mas ãh // eu gostava de subir naquele banquinho / eu gostava / adorava // mas eu perdi muito / tive muitos traumas no decorrer da / $\sigma^{a}$, 7a, 8a série / (E6, p. 3)

Intrigou-nos que, ao falar do trabalho com Língua Portuguesa na sala de aula, durante sua experiência de escolarização, tanto no RD16 (de E2 ${ }^{8}$ ) quanto no RD19 (de E6), os professores repetem: "ler as historinhas, $o$ barquinho amarela / lá aquelas coisas lá do quadro que ela [professora] escrevia" (RD19), "As frases que me marcaram no ensino da LP foi 'o barquinho é amarelo' 'a banana é amarela' 'a laranja é amarela' isso tá na minha cabeça como se fosse hoje se eu tivesse hoje na sala de aula e lendo isso tanto que me marcou"(RD16). É possível perceber que há uma ordem instituída que prima pela reprodução e homogeneidade, ainda mais quando lembramos que esses recortes são enunciados por dois professores que possuem, mais ou menos, dez anos de diferença de idade e, ainda assim, remetem à mesma cena do "barquinho amarelo". Ambos se referem às imagens do 'barquinho amarelo', associadas à escrita - "ela escrevia" (RD19) e "lendo isso" (RD16), o que corrobora a interpretação de serem repetiçôes da estrutura do LD.

\footnotetext{
${ }^{8}$ Vale lembrar que o E2 autodenomina-se descendente de alemães e afirma que a língua alemã é a sua LM. Já E6 autodenomina-se descendente de italianos e afirma que a sua LM é a LP com traços da língua italiana.
} 
Em vista desse funcionamento, questionamos: que língua é essa trabalhada pela instituição escolar?

A escola institui traços como determinantes do enunciador e de sua língua. Por exemplo, pelo contato com diferentes línguas, a criança apresenta, na sua língua, marcas sonoras, morfológicas, lexicais desse contato, o que nem sempre é aceito pela escola, por fugir ao 'padrão', ao 'normal'. Muitas vezes, a criança é tida como inapta para a 'língua da escola': "então por causa da minha entrada na escola / eu tive que deixar de lado o alemão / (...) / então por essa dificuldade de eu me adaptar com a LP por causa da minha LM" (RD16). Esses traços que não eram aceitos na escola precisavam passar por um processo de normalização. O enunciador teve embate com a língua da escola e precisou normalizar-se.

Segundo Hacking (2002), as instituições têm a função de estabilizar definiçõos e, nesse processo, a escola adquire um papel importante, já que os professores também exercem papel de normalizadores (idem, p. 542). A construção da ideia de 'normal' é grandemente suscitada por dicotomias: normal / anormal, sadio / doente, racional / irracional, responsável / irresponsável, estável / instável. Se pensarmos na instituição escolar, a maior parte de sua construção de saberes também é calcada em dicotomias - certo / errado, bom / mal, científico / não-científico, língua padrão / língua nãopadrão. Cada um desses pares é a expressão de um grupo de normas que têm a função de "regularizar, vigiar, enumerar, controlar, reformar, verificar, gerir, confinar, internar - em uma palavra, normalizar" (idem, p.541).

$\mathrm{Na}$ escola, essa normalização da língua se dá, frequentemente, pela repetição, como foi assinalado nas narrativas dos professores. São constrangidos e instados a 'normalizar-se' e inscrever-se na ordem do discurso sobre a língua apropriada na (para a) escola: uma língua que tende a apagar as marcas fonéticas, morfológicas e sintáticas da relação entre as línguas que constituem o enunciador, da sua identidade híbrida e multifacetada.

Os professores narram uma prática frequente nas instituições escolares da região, ou seja, a repetição para 'normalizar' traços de prosódia, marcas das línguas alóctones, tal como a presença de " $r$ " na fala de alunos. O então aluno era levado a 'abrir mão' dos traços de sua língua, da língua do aconchego da família. Não podemos esquecer que, "aquilo de que se abre mão junto com a língua vai fazer falta, porque faz falta no sujeito" (PAYER, 1999, p.13). Por meio desses $\mathrm{RDs}$, percebemos que a política da língua na escola é de silenciar o diferente em prol de uma imagem do que seja a língua ideal, sustentada pela 
gramática normativa. Sob o efeito desse freio e para se inserir na sociedade e por ela ser aceito, o enunciador submete-se às contingências da normalização.

Para Foucault, a instituição escolar desempenha papel importante na circulação social dos discursos:

[e]m escala muito mais ampla, é preciso reconhecer grandes planos no que poderíamos denominar a apropriação social dos discursos. Sabese que a educação, embora seja, de direito, o instrumento graças ao qual todo o indivíduo, em uma sociedade como a nossa, pode ter acesso a qualquer tipo de discurso, segue, em sua distribuição no que permite e no que impede, as linhas que estão marcadas pela distância, pelas oposições e lutas sociais. Todo sistema de educação é uma maneira política de manter ou de modificar a apropriação dos discursos, com os saberes e os poderes que eles trazem consigo (FOUCAULT, 1996, p. 43-44).

Uma imagem recorrente no corpus, intimamente correlacionada à representação de que, na língua do aluno, 'algo falta' e que esta falta deve ser subsumida pela língua dita padrão, é a de que o professor de Português tem 'mania' de correção gramatical, o que lhe confere um traço caracterizador de sua profissão. A escola, por meio de um processo de agenciamentos, estabelece uma hierarquização dos personagens da instituição escolar. Há secundarização do professor e do aluno em prol de um conhecimento instituído. Esse processo gera identificações e tentativas de estabilização de 'identidades', como observa Foucault (1996): "o que é afinal um sistema de ensino senão uma ritualização da palavra; senão uma qualificação e uma fixação dos papéis para os sujeitos que falam" (p. 44). Essa ritualização estabelece identificações aos enunciadores, fixa papéis e relações com a língua.

Contudo, não podemos esquecer que, "muito antes de ser objeto de conhecimento, a língua é o material fundador de nosso psiquismo e de nossa vida relacional" (REVUZ, 1998, p. 217); portanto, ela é constituída pelo equívoco, é múltipla.

Tendo em vista os recortes acima analisados, podemos afirmar que está em jogo, na narrativa dos professores, um funcionamento que se situa entre a normatização, a busca ilusória de uma língua ideal $e$ uma narrativa de si / sobre si e sobre sua língua, não levando em conta as fronteiras instituídas das línguas. Por isso, a partir dos recortes, não podemos falar em 'as línguas', como grupos passíveis de reunião, sem contradição. Abordamos, sim, a língua singular do enunciador, a língua que funciona no evento discursivo, marcado 
pela ruptura de fronteiras criadas pela cientificidade da linguística. A língua que se esfumaça, implode, se rompe e se (des)estrutura no dizer do professor sobre sua língua materna. Sua, mas também do outro, eu e o outro na mesma língua.

Os conflitos emergem no dizer e (des)velam diferentes posiçôes do professor e também permitem os gestos de resistência a um aparato normalizador; permitem ao enunciador 'pequenas revoltas cotidianas' e 'microrreconfiguração das relações de poder-saber' (FOUCAULT, 1995), possibilitam ao professor afirmar que "a gente subia no palco"(E6). Para ilustrar essa cena, apresentamos um recorte para destacar a pluralidade linguística da sala de aula, na região em estudo:

(RD1): [...] trabalho com crianças de primeira à quarta / em escolas multisseriadas / como eu trabalho idioma / tem um aluno que diz assim / oba hoje veio a profe espanhola e a profe brasileira / né / e ele é de origem italiana / né / então ele fala / profe / bah... como é parecido o espanhol com o italiano // (...) aí tem um aluno alemão lá e diz / em alemão é assim / sabe // porque a gente pega várias origens ali / né / na região (...) inclusive às vezes / falo com os alunos em alemão / nos intervalos / porque o espanhol pra eles é novo III já o alemão não III eles escutam em casa (...) eles adoram sabe I/I então por saber que eu também sei o alemão / dai eles se sentem mais em casa / posso falar porque a profe me entende II/ se têm os italianos na mesma escola / eles buscam uma palavrinha para também dizer que é parecido com o espanhol // eu acho que vou acabar aprendendo o italiano com eles (...) às vezes eu tenho até vontade de parar minha aula de espanhol pra ensinar até pros que sabem italiano um pouquinho de alemão e pra mim estar aprendendo o italiano (E1, p.4).

Por meio da narrativa acima, já que não acreditamos na interpelação perfeita, no ritual sem falhas, podemos considerar que os processos de normalização das línguas na escola 'falham', os sentidos não são jamais detidos - e o ser-estar-entre-línguas ${ }^{9}$ não o é tampouco. É interessante notar que o enunciador estabelece gestos de resistência às técnicas de governo, burla as regras

\footnotetext{
9 Ser-estar-entre-línguas é uma noção cunhada pela Dra. Maria José Rodrigues Faria Coracini, no projeto "O espaço híbrido da subjetidade: o ser (estar) entre línguas" (desenvolvido entre 2003 e 2007), inserido no Projeto Integrado "(Des)construindo identidades: formas de representação de si e do outro nos discursos sobre línguas (materna e estrangeira)", financiado pelo CNPq e sob sua coordenação.
} 
e permite a emergência de uma singularidade, permite-se "subir no palco" (RD19), às vezes falar com os alunos em alemão, italiano [...] Com isso, "eles se sentem mais em casa" (RD1).

O RD1 indicia a heterogeneidade constitutiva da língua(gem) da escola, apesar do escamoteamento e da ilusão de monolíngua instituídos. $\mathrm{O}$ hibridismo, o ser-estar-entre-línguas, emerge na enunciação dos professores, instaurando processos de identificação fluidos, em movimento e sem fronteiras linguísticas delimitadas. Pensar as maneiras plurais, híbridas dos modos de relação intersubjetiva, leva à compreensão de que situações tidas como desvios, falhas, contradições são constitutivas.

\section{Considerações finais}

Como percebemos nas análises até aqui empreendidas, não podemos falar em uma língua materna fundante, o que nos leva a afirmar que o acontecimento que liga o enunciador à(s) língua(s), a sua língua híbrida, é um fato de subjetividade, sujeito a resistências. Com isso, como consequência para a formação de professores, as dissonâncias deixam de ser vistas como problemas e se apresentam como constitutivas e produtivas, no processo de ensinoaprendizagem de línguas.

Este é um grande desafio que se põe à Linguística Aplicada: "aprender a lidar com o inefável, com o instável, com as contradiçôes" (CORACINI, 1997, p. 60), como inerentes e produtivas de todo e qualquer processo social, em particular a relação com as línguas, com a estranha-familiar língua da escola. Os RDs nos fazem perceber que "é possível ser brasileiro em muitas línguas" (OLIVEIRA, 2005).

Consideramos que uma das orientações para a formação de professores seja a pertinência em resgatar o que foi 'deixado de lado' (expressão do RD 16), em buscar discutir e analisar o funcionamento da cultura e das línguas de sua região, em dar relevo para a diferença, para os múltiplos processos identificatórios. Um dos modos de eles tocarem os fios do que foi deixado, mas que permanece como desejo, está no gesto de narrar a sua história.

Pelas análises, percebemos uma dupla injunção à qual o professor está submetido: ensinar a LP como língua padrão e também ensinar a LP no lugar da dita LM (alemão, italiano). Isso produz efeitos na sua identidade, tal como o apagamento de uma possível história marcada pelo contato entre línguas que convivem e instauram a língua híbrida do enunciador. 
O discurso pedagógico (DP) tende a trabalhar com o apagamento da enunciação, das diferenças e das multiplicidades; tenta ilusoriamente controlar, camuflar e negar o equívoco, apagando "a possibilidade de comparecimento do inconsciente, do sujeito" (RIOLFI, 1999, p. 40). No imaginário, isso deve ocorrer para não causar conflito que, então, tende a ser minimizado, apagado ou silenciado.

Contudo, os RDs que analisamos ao longo deste texto, trazem rastros do hibridismo, da pluralidade da língua na história da constituição linguística dos professores, consequentemente, da história deles. Os enunciadores ocupam diferentes posições discursivas que estão sempre em movimento. Movimento este muito produtivo no processo de formação dos professores, porque lhes permite a experiência com o diferente, com o múltiplo.

Um dos possíveis deslocamentos para a formação é a pertinência de o professor resistir à homogeneização provocada pelo discurso pedagógico, em prol do desejo da língua híbrida. Isso pressupõe ressignificar a noção de língua materna, o que carrega em si um desafio e uma responsabilidade, pois implica dar voz e vez às narrativas de memórias dos professores e dos alunos, às suas experiências de formação linguística e aos conflitos, tensões e equívocos daí decorrentes.

\section{Referências}

CORACINI, M. J. A escamoteação da heterogeneidade nos discursos da linguística aplicada e da sala de aula. Letras. Alteridade e heterogeneidade, n. 14, p. 39-63, jan.-jun. 1997.

CORACINI, M. J. A celebração do outro: arquivo, memória e identidade: línguas (materna e estrangeira), plurilinguismo e tradução. Campinas, SP: Mercado de Letras, 2007.

DERRIDA, J. O monoliguismo do outro. Ou a prótese de origem. Porto, Portugal: Campo das Letras, 2001.

FOUCAULT, M. História da sexualidade I: a vontade de saber. Rio de Janeiro: Graal, 1988.

FOUCAULT, M. Microfisica do poder. Rio de Janeiro: Graal, 1995.

FOUCAULT, M. A ordem do discurso. São Paulo: Edições Loyola, 1996.

FREUD, S. Lembranças encobridoras. In: Edição eletrônica brasileira das obras psicológicas de Sigmund Freud. Rio de Janeiro: Imago, 1899. 
HACKING, I. (2002). Façonner les gens. Disponível em: <www.college-defrance.fr/media/phi_his/ups1957_hackingrol02>. Acesso em: 07/09/2005.

IMPRESSÃO. In: HOUAISS, A.; VILLAR, M.S. Dicionário Houaiss da lingua portuguesa. Rio de Janeiro: Objetiva, 2007. p. 1585.

NETTO, A. D. S. Tramas da subjetividade no espaço entre-línguas: narrativas de professores de língua portuguesa em contexto de imigração. 2008. 243 f. Tese (Doutorado em Linguística Aplicada) - Instituto de Estudos da Linguagem, Universidade Estadual de Campinas, Campinas/SP., 2008.

NETTO, A. D. S. Sujeito e linguagem: (des)construindo identidade. Revista da Abralin, v. 6, n. 1, p. 129-146, 2007.

NETTO, A. D. S. "Estilhaços": a construção da subjetividade. Revista Contrapontos. UNIVALE - Universidade do Vale do Itajaí, SC, set.-dez. 2006.

OLIVEIRA, G. M. Linguas como patrimônio imaterial. 2005. Disponível em: <http://www.ipol.org.br>. Acesso em: 7 fev. 2007.

PAYER, M. O. Memória da língua. Imigração e nacionalidade. 1999. 173 f. Tese (Doutorado em Linguística) - Instituto de Estudos da Linguagem, Universidade Estadual de Campinas, Campinas/SP., 1999.

PAULILLO, R. A enunciação vacilante: formas do heterogêneo no discurso do si. 2004. 273 f. Tese (Doutorado em Linguística) - Instituto de Estudos da Linguagem, Universidade Estadual de Campinas, Campinas / SP., 2004

REVUZ, C. A língua estrangeira entre o desejo de um outro lugar e o risco do exílio. In: SIGNORINI, I. Lingua(gem) e identidade. Campinas: Mercado de Letras. São Paulo: Fapesp, 1998. p. 213-232.

RIOLFI, C. O discurso que sustenta a prática pedagógica. 1999. 360 f. Tese (Doutorado em Linguística) - Instituto de Estudos da Linguagem, Universidade Estadual de Campinas, Campinas / SP., 1999.

Recebido em março de 2009. Aprovado em maio de 2009. 